Neth. J. Pl. Path. 99 (1993) Supplement 3: 19-28

\title{
Effects of leaf blast on growth and production of a rice crop. 2. Analysis of the reduction in dry matter production, using two models with different complexity
}

\author{
L. BASTIAANS 1.2 \\ 1 Department of Theoretical Production Ecology, Wageningen Agricultural University, P.O. Box \\ 430, $6700 \mathrm{AK}$ Wageningen, the Netherlands \\ 2 International Rice Research Institute, Los Baños, Philippines
}

Accepted 13 September 1993

\begin{abstract}
Effects of leaf blast on dry matter production of rice observed in a field experiment were analysed in terms of cumulative radiation interception by green foliage (PARCUM; $\mathrm{MJm}^{-2}$ ) and radiation use efficiency (RUE; $g$ dry matter $\mathrm{MJ}^{-1}$ ). Leaf blast caused significant reductions in total dry matter production as a result of a decrease in PARCUM and a decrease in RUE. Reductions in radiation interception (RI; $\mathrm{MJm}^{-2} \mathrm{~d}^{-1}$ ) and RUE were first observed shortly after the introduction of the disease. RI was significantly reduced till maturity. The reduction in RUE disappeared towards maturity, simultaneous with a gradual decline in disease severity.

Analysis with a mechanistic model of crop growth showed that previously determined effects of leaf blast on leaf photosynthetic rate and respiration could explain the reduction in RUE during a large part of the growing season. During the first weeks after the onset of the disease the two effects were insufficient to fully explain the observed reduction in RUE. It was hypothesized that the unexplained part of the reduction in RUE in that period was a result of carbohydrate withdrawal by the pathogen for spore production.
\end{abstract}

Additional keywords: Oryza sativa, Pyricularia oryzae, radiation interception, radiation use efficiency.

\section{Introduction}

Rice crops (Oryza sativa L.) inoculated with Pyricularia oryzae Cav, during early growth stages showed a reduced $\mathrm{N}$-uptake, leaf area and sink formation (Bastiaans, 1993a). Analysis showed that the reduction in grain yield was solely source determined. The reduction reflected the reduction in total dry matter production, since the disease did not affect harvest index. In this paper the observed reduction in dry matter production is subjected to a more detailed analysis, using two crop growth models which differ in complexity.

Crop productivity can be analyzed in terms of solar radiation interception by green leaf area (RI; $\mathrm{MJm}^{-2} \mathrm{~d}^{-1}$ ) and radiation use efficiency (RUE; g dry matter $\mathrm{MJ}^{-1}$ ) (Monteith, 1977). Accordingly, Johnson (1987) distinguished two broad categories of effects of pests and diseases on crop growth: effects on RI and effects on RUE. Interpretation of leaf blast effects on canopy $\mathrm{CO}_{2}$ exchange rate with a model for canopy photosynthesis, demonstrated that leaf blast reduced RI as well as RUE (Bastiaans and Kropff, 1993). The analysis was limited to one development stage of the crop (maximum tillering), at 2 to 
3 weeks after inoculation. The first objective of the present study was to determine the time course of leaf blast effects on RI and RUE throughout the growing season.

A second model was used to analyse the causes of the reduction in the utilization efficiency of intercepted radiation. Previous studies indicated some of the mechanisms through which leaf blast reduces RUE. It was found that blast lesions, apart from a reduction in photosynthetically active leaf tissue, reduced the photosynthetic rate of the remaining green leaf tissue (Bastiaans, 1991). Additionally, dark respiration was increased as a result of infection (Bastiaans, 1993b). The second objective of this study was to determine whether the effects of leaf blast on leaf photosynthetic rate and repiration could sufficiently explain the reduction in RUE throughout the growing season. For this purpose the two effects were introduced in a mechanistic modcl of crop growth. Shoot dry weights simulated with the crop growth model were compared with those obtained experimentally.

\section{Materials and methods}

Field experiment. The effect of leaf blast on a rice crop was studied in an experimental field at the lowland research site of the International Rice Research Institute (IRRI), Los Baños, Philippines. A randomized complete block design with three treatments in five replicates was used. One treatment was used as the control (treatment A), while the other two treatments were inoculated with $P$. oryzae during early (treatment $\mathrm{C}$ ) and mid tillering (treatment B), respectively. From maximum tillering on, fungicides were used to stop the development of the disease, since an undisturbed further development would have destroyed the crop. Disease development and the effect of the disease on crop growth were studied through frequent harvesting (Fig. 1). Further experimental details were given by Bastiaans (1993a).

Separating effects of leaf blast on crop growth in effects on RI and effects on RUE. Radiation interception of photosynthetically active radiation by green foliage (RI; $\mathrm{MJm}^{-2} \mathrm{~d}^{-1}$ ) was calculated on a daily basis for every plot, using a model that consisted of the radiation routines of an elementary model of crop growth (Penning de Vries et al., 1989). Field observations on total leaf area, disease severity (fraction green leaf area covered by lesions) and fraction dead leaf area were used as model inputs. Values between observation dates were obtained by linear interpolation. Optical characteristics of diseased and dead leaf tissue were assumed to be identical to the characteristics of healthy leaf tissue. Data of daily total global radiation were obtained from IRRI's meteorological station. Photosynthetically active radiation (PAR; $400-700 \mathrm{~nm}$ ) was assumed to be $50 \%$ of the total global radiation.

The model was used to calculate the daily amount of PAR that penetrated the canopy, and the daily amount of PAR that was transmitted by the canopy. Their difference equals the intercepted amount of PAR, which was multiplied by the fraction green leaf area to obtain RI. The fraction green leaf area $\left(F_{\mathrm{L} . \text { Agren }}\right)$ was calculated as:

$$
F_{\text {LAgreen }}=\left(1-F_{\text {LAdcad }}\right) \times(1-x)
$$

in which $F_{\mathrm{LAdeal}}=$ fraction dead leaf area, and $x=$ disease severity. The fraction intercepted radiation $\left(R I_{f}\right)$ was defined as the ratio between $R I$ and incident PAR.

Till flowering only one canopy layer was distinguished, and RI was calculated under the assumption that lesions and dead leaf tissue were homogeneously distributed in the canopy. After flowering natural senescence occured, starting at the bottom of the canopy. 

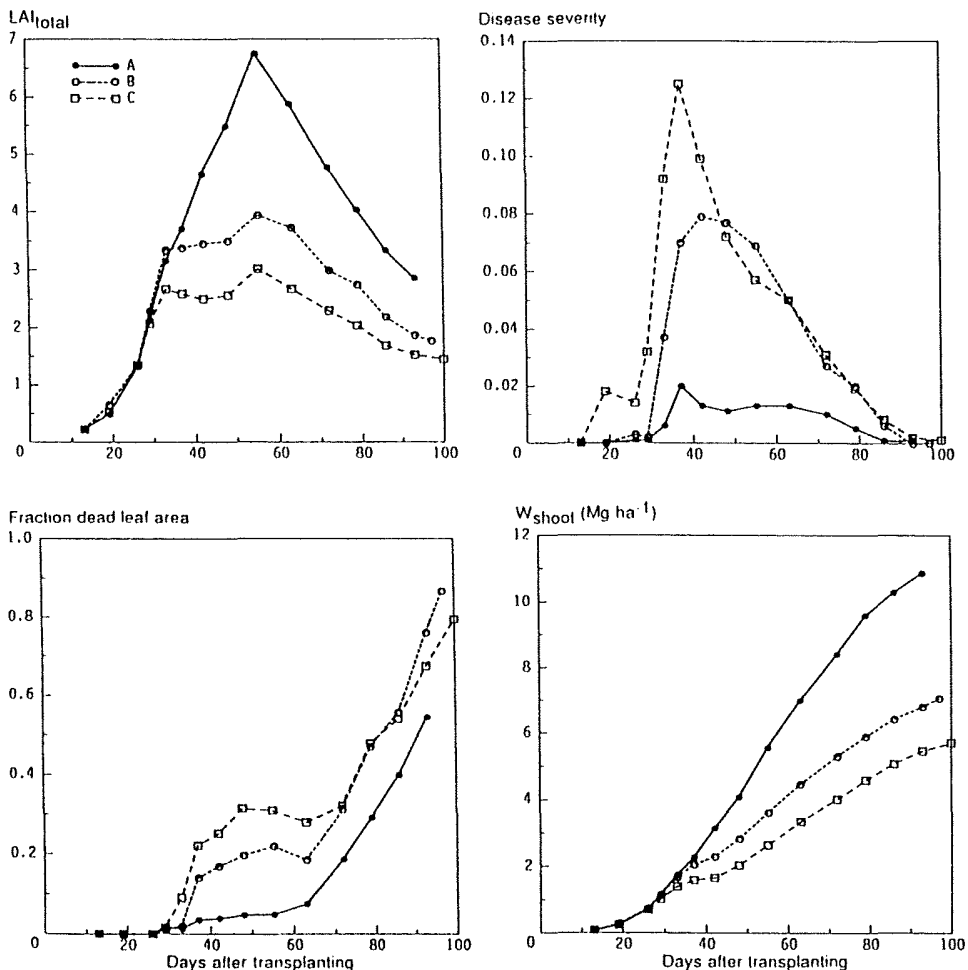

Fig. 1. Time course of total leaf area $\left(\mathrm{LAI}_{t(t): 1)} ;\right.$ ha ha $\left.{ }^{-1}\right)$, disease severity, fraction dead leaf area and shoot dry weight ( $\mathrm{W}_{\text {stow }} ; \mathrm{Mg}$ ha $^{-1}$ ) of rice in a control crop (Treatment $\mathrm{A}$ ) and in crops inoculated with Pyricularia oryzac (Treatments B and C). Graphs summarize the results of a previously described field experiment (Bastiaans, 1993a).

To account for the uneven distribution of dead leaf tissue, four canopy layers were distinguished. Radiation interception was calculated per layer, starting at the top of the canopy. RI of the canopy was obtained by adding up the RI of the four layers.

Cumulative radiation interception (PARCUM; $\mathrm{MJm}^{-2}$ ) was calculated for five successive periods of approximately 2 to 3 weeks. Radiation use efficiency (RUE; g dry matter $\mathrm{MJ}^{-1}$ ) for each period was calculated by dividing the observed increase in total dry matter by PARCUM.

A further analysis of leaf blast effects on RUE. An extended version of the MACROSLID model, of which a comprehensive description is given by Penning de Vries et al. (1989), was used to simulate the growth of the rice crop in every plot. MACROS-LID is an elementary crop growth model, which simulates the time course of dry matter production. The model simulates crop growth in production situations with an ample supply of water and nutrients, where growth is only determined by the incoming radiation, temperature and some physiological plant characteristics. The model operates with time steps of one day. The basis for the calculation of the daily dry matter production is the rate of gross $\mathrm{CO}_{2}$ assimilation of the canopy. This rate is calculated from the radiation profile in the 
Table 1. Experiment-specific crop variables, that were used as inputs to the crop growth model.

Crop variables

Units

Date of first and final harvest

Dry weight of leaves and stems at first harvest

$\left(\mathrm{kg} \mathrm{ha}^{-1}\right)$

Leaf Area Index as a function of time

Nitrogen content of green leaf tissue as a function of time

$\left(\mathrm{g} \mathrm{m}^{-2}\right)$

Disease severity as a function of time

Fraction dead leaf area as a function of time

Dry matter distribution over the shoot organs as a function of time

Fraction remobilizable stem dry weight at flowering

Relative death rate of green leaf tissue

canopy and the $\mathrm{CO}_{2}$ assimilation-light response of individual leaves. Part of the carbon fixed in the assimilation process is respired to provide energy for the biological functioning of the crop (maintenance). The remainder is incorporated into structural dry matter (growth). This daily dry matter increase is distributed over the various plant organs, in dependence of the phenological development stage of the crop. Numerical integration in time gives the time course of dry matter.

Effects of leaf blast on photosynthesis and respiration were introduced in the original version of the model, in an identical way as described by Bastiaans and Kropff (1993). The aim of the extended model was to determine whether the effects on leaf photosynthetic rate and respiration fully explain the reduction in the utilization efficiency of intercepted radiation. Since the model was used for an analysis of the backgrounds of leaf blast effects on RUE, the LAI was not simulated in the model, but the measured LAI was input to the model. This enables a restriction of the analysis of leaf blast effects on crop production to direct effects of the disease on physiological processes. Various model parameters were derived from the field experiment (Table 1). This further reduces the potential number of causes in case of a dissimilarity between simulated and observed dry matter production.

The relative death rate of leaves (RDR; $\mathrm{d}^{-1}$ ) after flowering was calculated from the observed decrease in green leaf weight. Such a standard derivation of the RDR before flowering is not possible, since changes in leaf weight before flowering are the net result of senescence of existing leaf tissue and formation of new leaf tissue. Therefore, the RDR of green leaf tissue before flowering was calculated from the increase in dead leaf tissue in that period:

$$
R D R=\left(W L V D_{12}-W L V D_{11}\right) /\left(0.5 \times\left(W_{L V G}+W_{11} V_{t_{12}}\right) \times\left(t_{2}-t_{1}\right)\right)
$$

where WLVD $=$ dry weight of dead leaf tissue $\left(\mathrm{kg} \mathrm{ha}^{-1}\right), \mathrm{WLVG}=$ dry weight of green leaf tissue $\left(\mathrm{kg} \mathrm{ha}^{-1}\right)$ and $\mathrm{t}_{1}$ and $\mathrm{t}_{2}$ refer to the dates of two successive harvests, expressed as days after transplanting. The thus calcultated RDR was related to the average of the disease severities observed at $t_{1}$ and $t_{2}$. The results obtained with the data from the individual plots were grouped in four severity classes. This led to a relation between disease severity and leaf senescence from which the rate of weight loss of green leaf tissue before flowering was derived (Fig. 2).

After initialization of the model with dry weights of leaves and stems of the first harvest, the model was run until final harvest. Model performance was evaluated by comparing the simulated and observed shoot dry weight in course of time. 


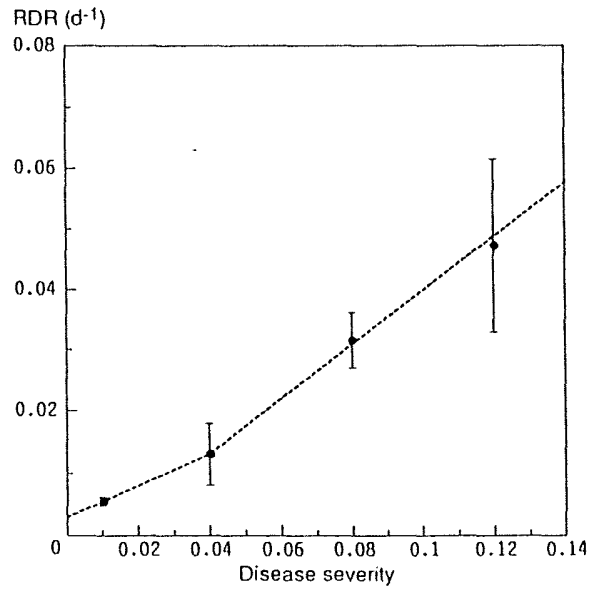

Fig. 2. Relation between disease severity of leaf blast and relative death rate of green leaf weight (RDR; $\mathrm{d}^{-1}$ ) of rice crops, as derived from field observations according to the procedure described in the text. The dotted line represents the relation used in the crop growth model to calculate the loss rate of green leaf weight before flowering. Vertical bars represent the standard errors of the mean.
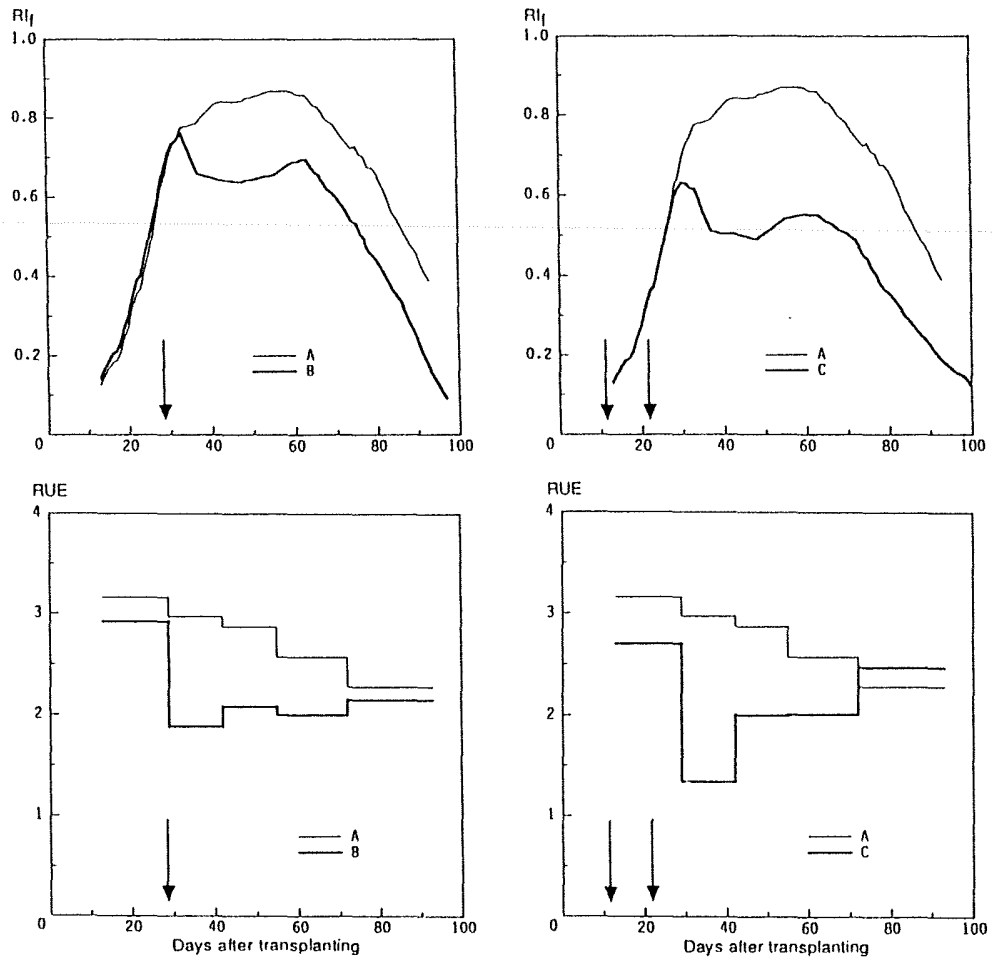

Fig. 3.Time course of the fraction of intercepted radiation $\left(\mathrm{RI}_{\mathrm{f}}\right)$ and the radiation use efficiency (RUE; g dry matter (MJ PAR) ${ }^{-1}$ ) of crops inoculated with Pyricularia oryzae (Treatment B and C). Thin lines are used to represent $\mathrm{RI}_{\mathrm{i}}$ and RUE of the control crop (Treatment A). Arrows indicate inoculation data.

Neth. J. Pl. Path. 99 (1993) Suppl. 3 


\section{Results}

Radiation interception and radiation use efficiency. Three distinguished phases are observed in the curve that describes the fractoon intercepted radiation of the control crop (Fig. 3). Till 38 DAT the fraction intercepted radiation increased rapidly (construction phase). Between 38 and 67 DAT more than $80 \%$ of the incident radiation was intercepted by the green leaf area of the crop. Saturation of light interception at LAl's over 4 was responsible for the flattening of the curve in this period (saturation phase). From 67 DAT on, light interception by green leaf area decreased rapidly as a result of leaf senescence (decline phase). The average radiation usc efficiency (RUE) of the control crop was 2.69 g dry matter (MJ PAR) ${ }^{-1}$ (Table 2). RUE decreased gradually towards maturity (Fig. 3).

Leaf blast caused significant reductions in both $\mathrm{RI}_{\mathrm{r}}$ and RUE (Fig. 3, Table 2). Radiation interception was already hampered in the construction phase, and remained low during the saturation phase of the control crop. The fraction of radiation intercepted in this period varied between 0.6 and 0.7 for treatment $B$, and between 0.5 and 0.6 for treatment C. Reduction of radiation interception began at the same time in healthy and inoculated crops, with almost equal rates of decline. Therefore, the differences in fraction intercepted radiation between control and diseased crops were maintained.

The reduction in RUE in the diseased crops showed a clear relation with disease severity. The strongest reduction in RUE was observed during the establishment of the disease, between 29 and 42 DAT (Fig. 3, Table 2). From then on RUE gradually recovered. Between 72 and 93 DAT, when disease severity had dropped to a low level, significant differences between RUE of the various treatments resolved.

Table 2. Cumulative radiation interception (PARCUM; $\mathrm{MJm}^{-2}$ ) and radiation use elficiency (RUE; g dry matter (MJ PAR) ${ }^{-1}$ ) of rice in a control crop (Treatment $A$ ) and in crops inoculated with Pyricularia oryzae (Treatment B, C), calculated for five consecutive periods. Values in parentheses express PARCUM and RUE as a fraction of the control.

\begin{tabular}{|c|c|c|c|c|c|c|c|c|c|}
\hline PARCUM & \multicolumn{3}{|c|}{ Treatment A } & \multicolumn{3}{|c|}{ Treattment B } & \multicolumn{3}{|c|}{ Treatment $\mathrm{C}$} \\
\hline 13-29 DAT & 34.4 & $(1.00)$ & $a^{2}$ & 37.2 & $(1.08)$ & a & 34.4 & $(1.00)$ & a \\
\hline 29-42 DAT & 66.6 & $(1.00)$ & $\mathrm{a}$ & 60.4 & $(0.91)$ & $b$ & 49.0 & $(0.74)$ & $\mathrm{c}$ \\
\hline 42-55 DAT & 84.4 & $(1.00)$ & $a$ & 62.6 & $(0.74)$ & $\mathrm{b}$ & 48.8 & $(0.58)$ & c \\
\hline 55-72 DAT & 110.2 & $(1.00)$ & $a$ & 84.8 & $(0.77)$ & b & 68.4 & $(0.62)$ & $\mathrm{c}$ \\
\hline 72-93 DAT & 107.2 & $(1.00)$ & $a$ & 70.4 & $(0.66)$ & $\mathrm{b}$ & 59.6 & $(0.56)$ & $b$ \\
\hline 13-93 DAT & 402.8 & $(1.00)$ & $\mathrm{a}$ & 315.4 & $(0.78)$ & b & 260.2 & $(0.65)$ & c \\
\hline \multicolumn{10}{|l|}{ RUE } \\
\hline 13-29 DAT & 3.16 & $(1.00)$ & $\mathrm{a}$ & 2.92 & $(0.92)$ & a & 2.70 & $(0.85)$ & $a$ \\
\hline $29-42$ DAT & 2.97 & $(1.00)$ & $\mathrm{a}$ & 1.88 & $(0.63)$ & $\mathrm{b}$ & 1.34 & $(0.45)$ & $\mathrm{b}$ \\
\hline 42-55 DAT & 2.87 & $(1.00)$ & $a$ & 2.08 & $(0.72)$ & b & 2.00 & $(0.70)$ & $\mathrm{b}$ \\
\hline 55-72 DAT & 2.57 & $(1.00)$ & $a$ & 2.00 & $(0.78)$ & b & 2.01 & $(0.78)$ & $\mathrm{b}$ \\
\hline 72-93 DAT & 2.28 & $(1.00)$ & $a$ & 2.15 & $(0.94)$ & a & 2.47 & $(1.08)$ & a \\
\hline 13-93 DAT & 2.69 & $(1.00)$ & $\mathrm{a}$ & 2.16 & $(0.8(0)$ & $\mathrm{b}$ & 2.10 & $(0.78)$ & $b$ \\
\hline
\end{tabular}



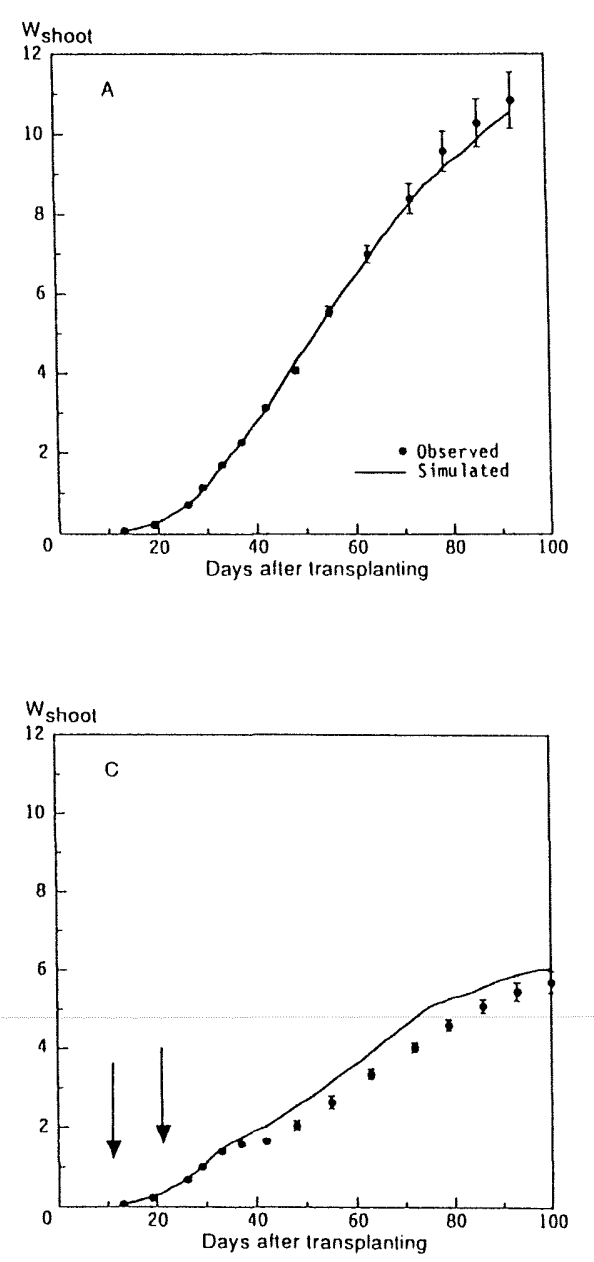

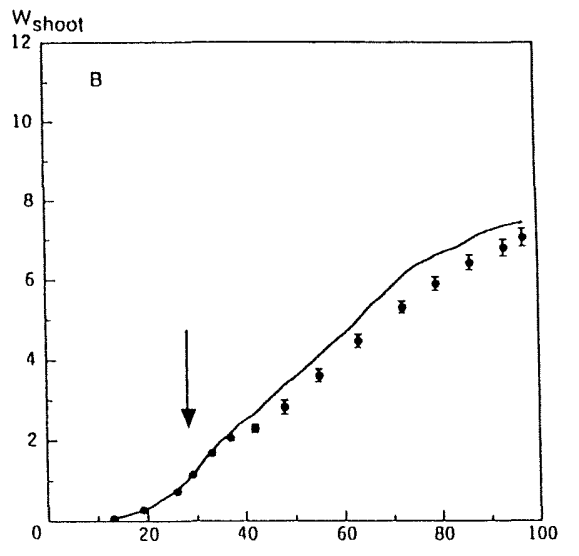

Fig. 4. Observed and simulated shoot dry weight $\left(\mathrm{W}_{\text {shoot }} ; \mathrm{Mg} \mathrm{ha}^{-1}\right)$ of rice in a control crop (Treatment A) and in crops inoculated with Pyricularia oryae (Treatments B, C). Vertical bars represent the standard errors of the mean. Arrows indicate inoculation data.

Simulation of dry matter production. Simulation of dry matter production of the control crop resulted in a good agrcement with the observed dry matter production (Fig. 4). This demonstrates the thoroughness of the assimilation and respiration routines of the crop growth model and indicates that any dissimilarity between simulated and observed shoot dry weight of the inoculated crops is likely to be due to an error in the simulation of leaf blast effects.

Total dry matter production of the inoculated crops was overestimated. The overestimation appeared during the first weeks after the onset of the disease. After that time the difference between simulated and observed dry weight stabilised at approximately 550 $\mathrm{kg} \mathrm{ha}^{-1}$, in both treatments. The overestimation indicates that during the establishment of the disease the effects of leaf blast on leaf photosynthetic rate and respiration were inadequate to fully explain the reduction in crop growth rate. The stabilisation of the overestimation in the consecutive period till maturity indicates that later on the two effects gave a sufficient explanation of the reduction in RUE. 


\section{Discussion}

The analysis with the RIXRUE model confirms that leaf blast in rice is a pathosystem in which the pathogen reduces the dry matter production of the crop through a reduction in cumulative radiation interception and a reduction in radiation use efficiency (Bastiaans and Kropff, 1993). The difference in overall RUE between the inoculated crops (treatments B and C) was not significant (Table 2). Therefore, the difference in total dry matter production between $\mathrm{B}$ and $\mathrm{C}$ resulted mainly from a difference in cumulative radiation interception. After initiation of the disease, lesion coverage and disease induced senescence caused a direct reduction of RI. An indirect reduction of RI as a result of leaf blast was caused by a decline in new leaf area formation. This decline resulted from a reduced crop growth rate, which was caused by previous reductions of leaf blast on RI and RUE. The importance of this mechanism depends strongly on the development stage of the crop, since the underlying positive feedback between crop growth, leaf area lormation and radiation interception is strongest during early growth stages (Blackman, 1919). Previously, Lim and Gaunt (1986) and Van Oijen (1991) pointed at the importance of the available leaf area at initiation of a disease for leaf area duration and cumulative radiation interception. It can be concluded that the difference in LAI at the initiation of leaf blast, caused by the difference in inoculation date, was the most prominent factor responsible for the observed differences in total dry matter production of the inoculated treatments in this experiment.

During the establishment of the disease the effects of leaf blast on leaf photosynthetic rate and respiration were inadequate to fully explain the observed reduction in RUE. The utilization of intercepted radiation for dry matter production can be subdivided into three processes: $\mathrm{CO}_{2}$-assimilation, allocation of assimilates and utilization of assimilates for dry matter production. In an earlier study, it was demonstrated that the effects of leaf blast on leaf photosynthetic rate and respiration satisfactory explained the effect of leaf blast on $\mathrm{CO}_{2}$-assimilation (Bastiaans and Kropff, 1993). The overestimation of shoot dry weight after the onset of the disease observed in this study therefore most likely results from an effect of leaf blast on either one of the last two processes.

An increased allocation of assimilates to the roots would be an appropriate explanation for the observed dissimilarity between observed and simulated shoot dry weight. Since root biomass was not determined in the field experiment, this hypothesis could not be validated. However, according to the functional balance theory of Brouwer (1962), an attack by a foliar disease and the succeeding reduction in crop photosynthesis is more likely to be followed by an increased allocation of assimilates to the shoot. Such a shift in the allocation pattern of assimilates was for instance observed in wheat after infection with Puccinia striiformis (Siddiqui and Manners, 1971). An increased allocation of assimilates to the roots after infection of rice with leaf blast is therefore considered to be unlikely.

Consequently, the overestimation of shoot dry weight is probably caused by a less efficient utilization of produced carbohydrates for crop growth. In a study on the effect of leaf rust on crop production of winter wheat, Van Roermund and Spitters (1990) introduced the uptake of assimilates by the fungus for spore production as a potential damagemechanism. They estimated that the pathogen used 230 to $570 \mathrm{~kg} \mathrm{CH}_{2} \mathrm{O}$ ha $^{-1}$ for spore production and related processes. Data on the rate of sporulation of blast lesions are diverging, but data on the production pattern of the lesions are rather uniform (Kato et al., 1970; Kato and Kozaka, 1974; Ou, 1985; Kim et al., 1987). Lesions start to produce spores immediately after their appearance, and spore production may last for 20 to 30 days. Spore production reaches its peak between 3 to 8 days after lesion appearance, and $90 \%$ or more 

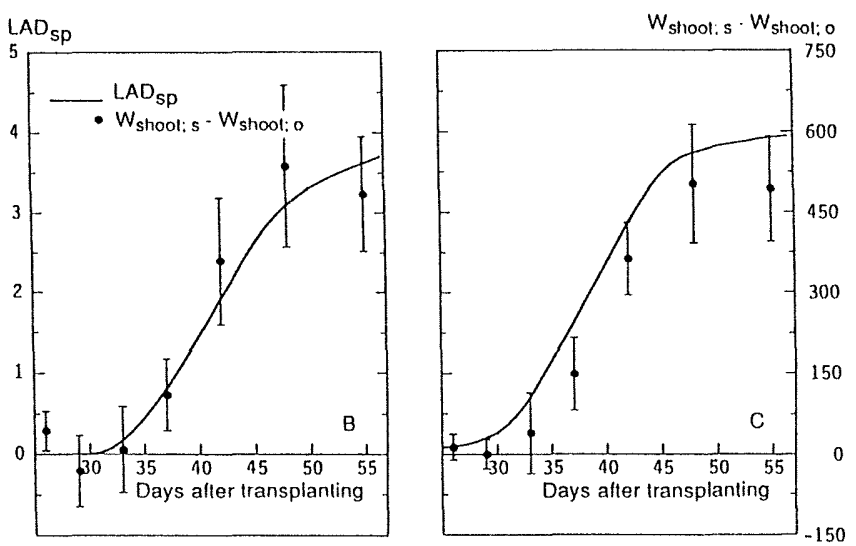

Fig. 5. Simulated leaf area duration of sporulating blast lesions $\left(\mathrm{LAD}_{\mathrm{sp}} ; \mathrm{d}\right)$ and the difference between simulated and observed total shoot dry weight $\left(\mathrm{W}_{\text {strowt: }}-\mathrm{W}_{\text {shool; o }} ; \mathrm{kg} \mathrm{ha}^{-1}\right)$ for rice crops inoculated with Pyricularia oryzae (Treatments B and C). Vertical bars represent the standard errors of the mean.

of the spores are produced during the first 14 days. These last observations were used to simulate the amount of actively sporulating leaf area in the various plots of the experiment. For each day the leaf area occupied with lesions (Diseased Area Index (DAI); Zadoks, 1961) was calculated through multiplication of the green leaf area index and disease severity. The newly colonized leaf area was calculated daily and derived from the increase in DAI. Next, the amount of actively sporulating leaf area for any particular day was estimated through summation of the amount of leaf tissue that was colonized during the last 14 days. Integration of the daily amount of actively sporulating leaf area over time yields the leaf area duration of sporulating leaf tissue $\left(L A D_{s p}\right.$ in $\left.d\right)$. The time course of this integral shows a striking similarity with the time course of the difference between simulated and observed shoot dry weight (Fig. 5). If the overestimation of shoot dry weight was completely caused by the use of carbohydrates by the pathogen for spore production, the growth reduction per ha sporulating leaf tissue would amount to approximately $150 \mathrm{~kg}$ dry matter $\mathrm{d}^{-1}$. This corresponds to a carbohydrate withdrawal of around $200 \mathrm{~kg} \mathrm{CH}_{2} \mathrm{O}$ (ha sporulating lesions) $)^{-1} \mathrm{~d}^{-1}$.

Use of crop growth models in studies on crop loss reflects the growing awareness among plant pathologists that the remaining healthy leaf area, rather than the severity of the disease, forms a solid basis for crop loss assessment (Waggoner and Berger, 1987). In this study two different types of crop growth models were used to analyse the reduction in dry matter production in rice dıc to leaf blast. Recently, Rossing et al. (1992) discussed the merits and limitations of each approach. They concluded that the RI $\times$ RUE approach is a good starting point for analysis, because of the conceptual simplicity and the ease of empirical parameter estimation. This approach allows two broad categories of disease effects to be distinguished: effects on RI and effects on RUE. For more detailed analysis, especially of disease effects on RUE, the use of mechanistic crop growth models is required. The present study illustrates these conclusions. 


\section{Acknowledgements}

Thanks are due to Prof. Dr J.C. Zadoks and Prof. Dr Ir R. Rabbinge for comments on earlier versions of the manuscript.

\section{References}

Bastiaans, L., 1991. Ratio between virtual and visual lesion size as measure to describe reduction in leaf photosynthesis of rice due to leal blast. Phytopathology 81: 611-615.

Bastiaans, L., 1993a. Effects of leaf blast on growth and production of a rice crop. 1. Determining the mechanism of yield reduction. Netherlands Journal of Plant Pathology 99: in press.

Bastiaans, L., 1993b. Effects of leaf blast on photosynthesis of rice. 1. Leaf photosynthesis. Netherlands Journal of Plant Pathology 99: 197-203.

Bastiaans, L. \& Kropff, M.J., 1993. Effects of leaf blast on photosynthesis of rice. 2. Canopy photosynthesis. Netherlands Journal of Plant Pathology 99: 205-217.

Blackman, V.H., 1919. The compound interest law and plant growth. Annals of Botany 33: 353-360.

Brouwer, R, 1962. Nutritive influences on the distribution of dry matter in the plant. Netherlands Journal of Agricultural Science 10: 399-408.

Johnson, K.B., 1987. Defoliation, disease and growth: a reply. Phytopathology 77: 1495-1497.

Kato, H. \& Kozaka, T., 1974. Effect of temperature on lesion enlargement and sporulation of Pyricularia oryzae in rice leaves. Phytopathology 64: 828-830.

Kato, H., Sasaki, T. \& Koshimizy, Y., 1970. Potential for conidium formation of Pyricularia oryacae in lesions on leaves and panicles of rice. Phytopathology 60: 608-612.

Kim, C.K., Yoshino, R. \& Lee, E.J., 1987. Epidemiological studies of rice blast disease caused by Pyricularia oryzae Cavara. II. Sporulation and conidia release from naturally infected lesions. Korean Journal of Plant Protection 26: 37-41.

Lim, L.G. \& Gaunt, R.E., 1986. The effect of powdery mildew (Erysiphe graminis f. sp. hordei) and leaf rust (Puccinia hordei) on spring barley in New Zealand. I. Epidemic development, green leaf area and yield. Plant Pathology $35: 44-53$.

Monteith, J.L., 1977. Climate and the efficiency of crop production in Britain. Philosophical Transactions of the Royal Society of London, Series B 281: 277-294.

Ou, S.H., 1985. Rice diseases. Commonwealth Agricultural Bureau, Kew, Surrey, England. 380 pp.

Penning de Vries, F.W.T., Jansen, D.M., ten Berge, H.F.M. \& Bakema, A., 1989. Simulation of ecophysiological processes of growth in several annual crops. Pudoc, Wageningen. $271 \mathrm{pp}$.

Rossing, W.A.H., Van Oijen, M., Van der Werf, W., Bastiaans, L. \& Rabbinge, R., 1992. Modelling the effects of foliar pests and pathogens on light interception, photosynthesis, growth rate and yield of field crops. In: Ayres, P.G. (Ed.), Pests and pathogens: plant responses to foliar attack. Bios Scientific Publishers Ltd., Oxford. p. 161-180.

Siddiqui, M.Q. \& Manners, J.G., 1971. Some effects of general yellow rust (Puccinia striiformis) infection on ${ }^{14}$ carbon assimilation and growth in spring wheat. Journal of Experimental Botany 22: $792-799$.

Van Oijen, M., 1991. Leal area dynamics of potato cultivars infected by Phytophthora infestans. Netherlands Journal of Plant Pathology 97: 345-354.

Van Roermund, H.J.W. \& Spitters, C.J.T., 1990. Simulation of yield reduction by leaf rust in winter wheat, applied to the analysis of genetic variation in partial resistance. Netherlands Journal of Plant Pathology 96: 17-28.

Waggoner, P.E. \& Berger, R.D., 1987. Defoliation, disease and growth. Phytopathology 77: 393-398.

Zadoks, J.C., 1961. Yellow rust on wheat, studies in epidemiology and physiologic specialization. Tijdschrift over Plantezickten 67: 69-256. 